\title{
Miniature Pigs' Abilities to Discriminate People Based on Their Photographs
}

\author{
YUKI KOBA ${ }^{122)}$, AI MORITA ${ }^{11}$, JEFF RUSHEN ${ }^{3)}$, \\ ANNE MARIE DE PASSILlé' ${ }^{3)}$ and HAJIME TANIDA ${ }^{11}$
}

\begin{abstract}
This study examined whether miniature pigs could discriminate people based on their photographs. In experiment 1 , the pigs were trained to discriminate between two people in the Y maze. All pigs successfully discriminated between the persons. The pigs were then tested with photographs of those same people, but no pigs discriminated between the photographs. In experiment 2, three pigs were trained to discriminate between photographs of people. Then they were tested to determine whether they could discriminate the same people. Some pigs appeared to discriminate between one pair of people but not the other pairs. In experiment 3, four pigs were used to test whether they had learned to discriminate between photographs of people learned more quickly to discriminate them than pigs that had learned to discriminate between two-dimensional abstract figures. The number of sessions to discriminate between people was not affected by the treatment. Results show that pigs can learn to discriminate between people and between photographs of people, but they had difficulty in discriminating the people based on their photographs.
\end{abstract}

Key words : Pigs, Learning, Discrimination, Human-animal relationships, photographic images

\section{Introduction}

Farm animals such as cattle (Boivin, Garel, Mante \& Le Neindre, 1998; Munksgaard, de Passillé, Rushen \& Ladewig, 1999; Munksgaard, de Passillé, Rushen, Thodberg \& Jensen, 1997; Taylor \& Davis, 1998), sheep (Boivin, Nowak, Després,

1) Graduate School of Biosphere Science, Hiroshima University

1-4-4 Kagamiyama Higashi-Hiroshima, 739-8528 Japan

2 ) currently: Faculty of Child Science \& Education, Teikyo University of Science

2-2-1 Senjusakuragi Adachi-ku, Tokyo, 120-0045 Japan

3) Pacific Agri-Food Research Centre, Agriculture and Agri-Food Canada

Aggassiz, BC VOM 1AO Canada

Corresponding author: YUKI KOBA

E-mail: yukikoba@ntu.ac.jp

Published online in J-STAGE: July 7, 2012

doi: 10.2502/janip.62.1.10
Tournadre \& Le Neindre, 1997; Davis, Norris \& Taylor, 1998) and commercial cross bred pigs (Tanida, Miura, Tanaka \& Yoshimoto, 1994, 1995) respond differently to different people based on their previous experience with those people, suggesting that farm animals can discriminate individual people. Research has begun to examine the cues used in this discrimination. For example, dairy cattle can discriminate between people wearing clothes of different colours (de Passillé, Rushen, Ladewig \& Petherick, 1996; Munksgaard, de Passillé, Rushen, et al., 1997; Munksgaard, de Passillé, Rushen, et al., 1999; Rybarczyk, Rushen \& de Passillé, 2003) while some adult cows appear to be able to use either body height or the facial features to discriminate between people; however, the discrimination of the face alone is more difficult when the cows cannot view the rest of body (Rybarczyk, Koba, Rushen, Tanida \& de Passillé, 2001). 
Tanida and Nagano (1998) examined the ability of the miniature pigs to discriminate between people and to identify the cues used by the pigs for discrimination between people. The pigs were able to discriminate between a stranger and their familiar handler using a combination of visual, auditory and olfactory cues, but olfactory cues alone were of little importance. In a subsequent study (Koba \& Tanida, 1999), the miniature pigs appear to discriminate between a familiar handler and an unfamiliar person primarily on the basis of visual cues, prominent among which is the colour of clothing. However, the miniature pigs can discriminate between people on the basis of differences in body size and partly by facial cues when exposed repeatedly to people wearing clothes of the same colour (Koba \& Tanida, 2001).

These studies suggest that cows, commercial pigs and miniature pigs are able to discriminate between different people by using visual cues, but it has not been reported whether pigs are able to discriminate people based on their photographs. According to Koba and Tanida (2007), it seems that ponies might be able to transfer knowledge of visual cues of people to discrimination of photographic images. Similarly, sheep are able to discriminate their conspecifics and humans when pictures were projected on a screen (Kendrick,
Atkins, Hinton, Broad, Fabre-Nys \& Keverne, 1995; Kendrick, Atkins, Hinton, Heavens \& Keverne, 1996).

This study examined the extent that miniature pigs could generalize learned discriminations from people to photographs of those people and vice versa.

\section{Materials and methods}

All procedures involving animal handling and treatment complied with the Committee for Animal Use and Care of Hiroshima University, Japan.

\section{Animals and housing}

Five Göttingen Miniature pigs were used. Three pigs (2 females: Pig1, Pig2 and 1 castrated male: Pig3) were 6 months old, and 2 pigs (females: Pig4 \& Pig5) were 4 months old when the experiments started. They were housed as two groups (one of older pigs and one of younger pigs) in rooms $(3.16 \times 1.95 \mathrm{~m})$ of the experimental facility. They were fed at fixed times (09.00 and $15.30 \mathrm{~h}$ ) each day. The 3 older pigs were fed a commercial ration (TDN: $73 \%$ and crude protein: $12 \%$ ) and the 2 younger pigs were fed a commercial weaner ration. Water was available $a d$ libitum. A single caretaker wearing grey coveralls fed them and cleaned the pen every day.

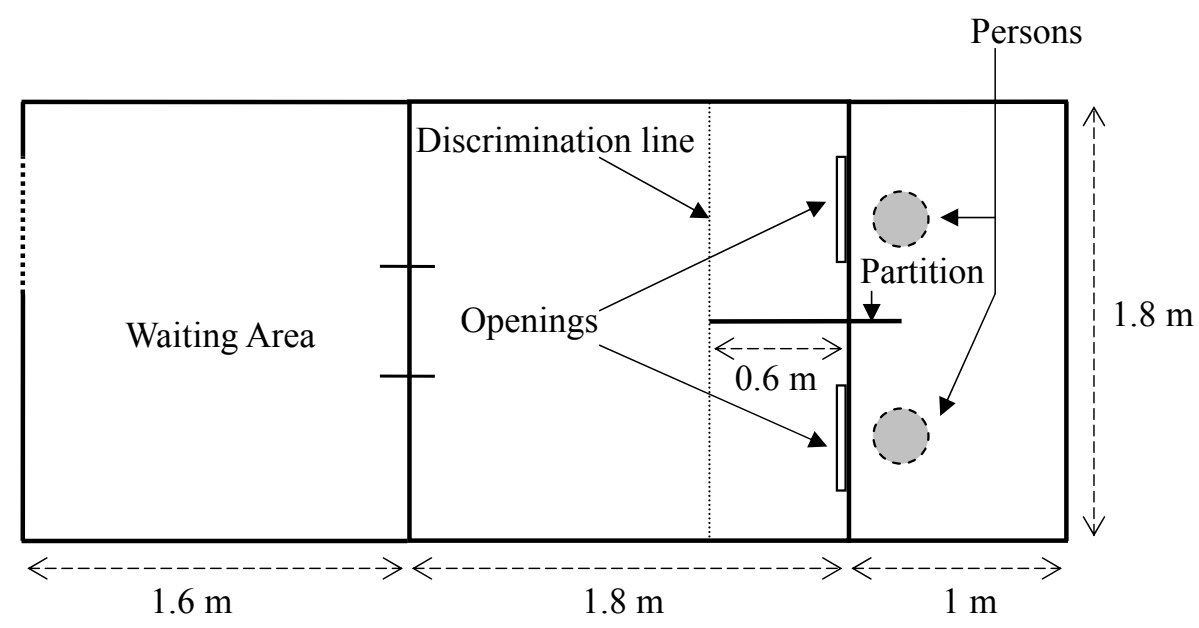

Figure 1. Diagrammatic representation of the Y-maze. 


\section{Equipment}

A Y-maze (Figure 1) was installed in an experimental room next to the pigs' home rooms and placed next to a waiting pen (1.8 $\mathrm{m} \times 1.6 \mathrm{~m})$. The front panel of the Y-maze had two openings $(0.7 \mathrm{~m} \times 0.5 \mathrm{~m}$ for Exp. 1 and $0.55 \mathrm{~m} \times 0.5 \mathrm{~m}$ for Exp. $2 \& 3$ at $0.7 \mathrm{~m}$ from the ground). A partition board (height 0.9 $\mathrm{m} \times$ length $0.6 \mathrm{~m}$ ) was set up in between the openings.

\section{Training procedures}

Before training began, the pigs were introduced in their groups to the maze for 1-h per day for 3 days. In the first training phase, the pigs were trained together for 2 days, as it has been reported that fear is reduced when pigs are in groups (Nicol \& Pope, 1994). Then, for each pig, a person (female wearing blue long-sleeved cloth coveralls) sat in one of the arms of the maze with the arm chosen randomly. When the pig crossed the discrimination line of the correct arm (in which the person was sitting), the pig was rewarded with small (I cm diameter) biscuits through a hole $(3 \mathrm{~cm}$ diameter) of the front panel of the maze by an experimenter who was not the stimulus person in the experiments. When the pig crossed the line of the incorrect side, a bell was rung and no reward was given. The pigs were trained to go back to the waiting area after each trial. One session consisted of 20 trials. The training was continued until all the pigs chose the correct arm at least 15 times among 20 trials $(p<.05$ by Chi square test).

\section{General Experimental procedures}

Three experiments were started after the pigs had passed the criterion of success during the training. All tests were conducted in the maze between 10.30 and $17.30 \mathrm{~h}$. A person who was not involved in the experiments wearing grey coloured coveralls transferred the pigs between their room and the experimental apparatus before and after each experiment.

Pigs were trained to discriminate either between two people or between two photographs of the same two people. The protocol of reinforcement was the same as the training procedure. When the pigs were tested with the people, two people (the rewarder and the non-rewarder) sat motionless in a chair facing the pig, one person in each arm of the maze. Only the upper halves of the bodies of the experimenters were visible to the pig. Both people wore blue coveralls in the experiments because it is known that the pigs can use the colour of clothing to discriminate between people (Tanida \& Nagano, 1998; Tanida, Senda, Suzuki, Tanaka \& Yoshimoto, 1991). Colour photographs of the sitting rewarder and nonrewarder were taken through the opening of the front panel of the maze with a digital camera (Canon, Ixy Digital 500), enlarged to life-size and printed on a super fine glossless rectangular paper. When the pigs were tested with photographs, the photographs of the rewarder and the non-rewarder were placed in the openings of front panel so that the photographs looked as the actual people were sitting. In experiment 3 , photographs of abstract figures (circle or cross) were additionally used (described below).

Each pig was subjected either daily, or twice per day, to a session of 20 trials. For 20 trials, the position of the experimenters, photographs or abstract figures was randomly assigned according to the Gellermann series (Gellermann, 1933). Each trial finished when the pig stepped across the discrimination line. The pig was rewarded only when it chose either the rewarder or the photograph of the rewarder. The protocol of reinforcement was the same as the training procedure. The order at which the pigs were exposed to test sessions was at random within each treatment. The criterion for successful discrimination was that a pig made at least 15 correct choices $(p<.05$ : Chi square test $)$ among 20 trials in two consecutive sessions. 


\section{Experimental procedures and results}

\section{Experiment 1}

\section{Objectives}

In experiment 1, the pigs were tested to determine whether they could generalize a learned discrimination between two people to photographs of the two people.

\section{Procedures}

All five miniature pigs were used. Four female people (A, B, C, D), who were previously unfamiliar to the pigs, participated for the experiment as 2 pairs of a rewarder and a non-rewarder. Pig1, Pig2 and Pig3 were tested with the pair of $A \& B$, and Pig4 and Pig5 were tested with the pair of C\&D. When the pigs passed the test, they were then tested with two-dimensional colour photographs of those same people in the same experimental conditions. The sessions with the photographs were limited to a maximum of two to avoid the pigs learning to discriminate between the photographs themselves. The success criterion for the test was one session with 15 or more correct choices in 20 trials $(p<.05$ by Chi square test).

\section{Results}

As shown in Figure 2, all five pigs successfully discriminated between the two people $(p<.025$ by Chi square test). There were individual differences between the pigs in the number of sessions needed, which ranged from 4 to 12 . However, when the pigs were tested with the photographs of the two people, no pigs correctly discriminated between the photographs within the maximum
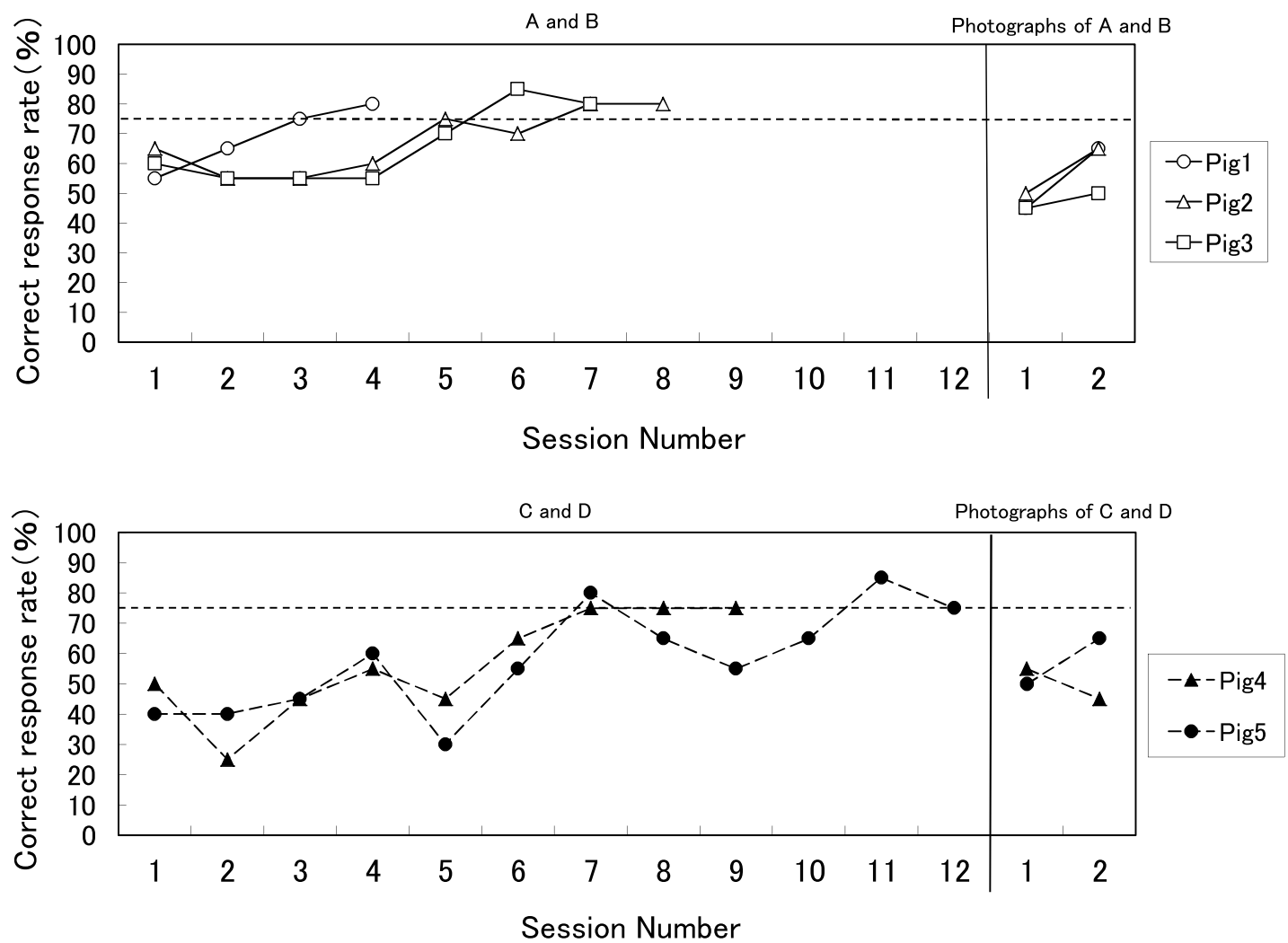

Figure 2. The correct response rate (percentage of trials in which the pig chose the rewarder) of each pig in Experiment 1. The dotted horizontal line indicates the criterion of discrimination (75 \% correct choice rate: $p<.05$ by Chi square test). 
of two sessions.

\section{Experiment 2}

\section{Objectives}

In experiment 2, the pigs were tested to determine whether they could generalize a learned discrimination between two photographs of people to the two people themselves.

\section{Procedures}

Three of the miniature pigs used in the previous experiment, Pig1, Pig2 and Pig3, were used. Six female people (E, F, G, H, I, J), who were previously unfamiliar to the pigs and who had not participated in experiment 1 were assigned to 3 pairs of a rewarder and a non-rewarder $(\mathrm{E} \& \mathrm{~F}, \mathrm{G} \& \mathrm{H}, \mathrm{I} \& \mathrm{~J})$. All pigs were tested with all three pairs of people.

The pigs were first taught to discriminate between two-dimensional colour photographs of the 3 pairs of people. When the pigs reached the criterion of success, they were then tested with those same people. The sessions with the people were limited to a maximum of two to avoid the pigs learning to discriminate between the people themselves. The success criterion for the test was one session with 15 or more correct choices in 20 trials $(p<.05$ by Chi square test).

\section{Results}

As shown in Figure 3, Pig1 and Pig2 successfully discriminated between the photographs of the two people in all 3 pairs according to the success criterion $(p<.025$ by Chi square test). Pig3 discriminated the photographs of G\&H and I\&J, but was not able to discriminate the photographs of E\&F. There were individual differences between the pigs in the number of sessions needed, which ranged from 2 to 17 . When they were tested with the real people after the sessions with the photographs, Pig1 reached the criterion of success in the 2nd session of the test of $\mathrm{E} \& \mathrm{~F}$ but failed to discriminate $\mathrm{G} \& \mathrm{H}$ and I\&J. Pig2 exceeded $75 \%$ correct choice rate in the 1st session of the test of $\mathrm{E} \& \mathrm{~F}$ but failed to discriminate $\mathrm{G} \& \mathrm{H}$ and I\&J. Pig3 was not able to discriminate any of the pairs of people.

\section{Experiment 3}

\section{Objectives}

In experiment 3 , the pigs were tested to verify our hypothesis that the pigs that had learned to discriminate between photographs of a rewarder and a non-rewarder learned more quickly to discriminate between the people than pigs that had learned to discriminate between photographs of twodimensional abstract figures (circle or cross).

\section{Procedures}

Four miniature pigs, Pig1, Pig2, Pig4 and Pig5 were used. One male (K) and 3 female people $(\mathrm{L}, \mathrm{M}, \mathrm{N})$ participated in the experiment, and were assigned to 2 pairs of a rewarder and a non-rewarder (K\&L and $\mathrm{M} \& \mathrm{~N})$. Colour photographs of two abstract figures, a black circle (diameter: $0.35 \mathrm{~m}$ ) and cross (width and height: $0.35 \times 0.35 \mathrm{~m}$ ), were also printed on super fine paper.

Pigs 2 and 4 first learned to discriminate between the two abstract figures and, once they had reached the criterion of success, they were then tested for their ability to discriminate between the rewarder and nonrewarder. Pigs 1 and 5 were first trained to discriminate between photos of the rewarder and non-rewarder (pair K \& L) and were then tested for their ability to discriminate between the rewarder and non-rewarder. The treatments were then reversed (and pair $\mathrm{M} \&$ $\mathrm{N}$ was used). A maximum of 2 sessions was allowed for the pigs to discriminate between the two people. The success criterion for the test was one session with 15 or more correct choices in 20 trials $(p<.05$ by Chi square test).

\section{Results}

As shown in Figure 4, all 4 pigs successfully discriminated either between the photographs of two people or between the abstract figures $(p<.025$ by Chi square test). However, 


\begin{tabular}{lll}
\hline- -Pig1 & - Pig2 & $-\square$-Pig3 \\
\hline
\end{tabular}

$E \& F$
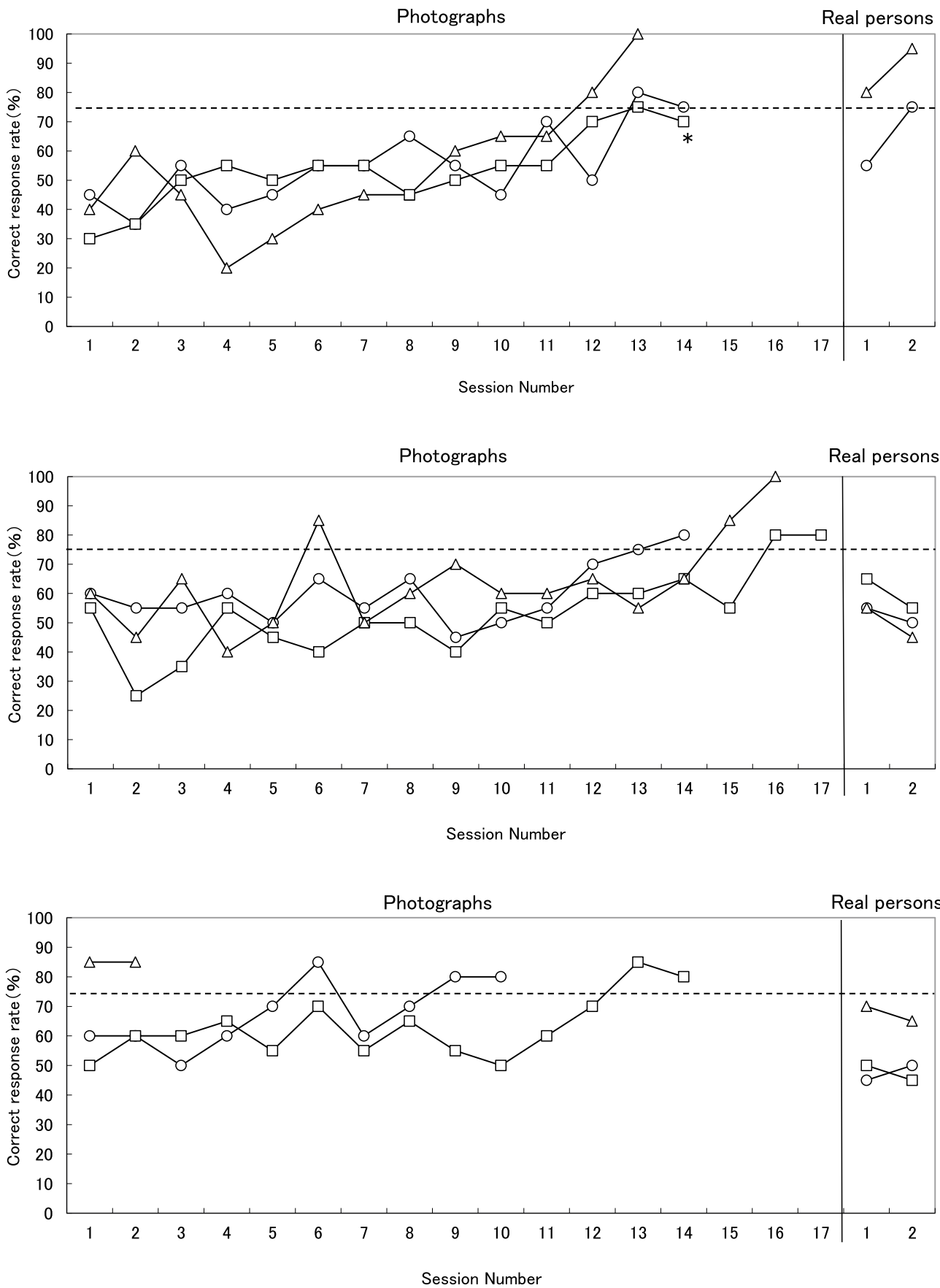

Figure 3. The correct response rate of each pig in Experiment 2. The dotted horizontal line indicates the criterion of discrimination ( $75 \%$ correct choice rate: $p<.05$ by Chi square test). Asterisk: After 14th session, Pig 3 showed the tendency of side preference and the pig did not choose neither arm in some trials. Therefore we judged that it was not possible for the pig to proceed the rest of the tests. 

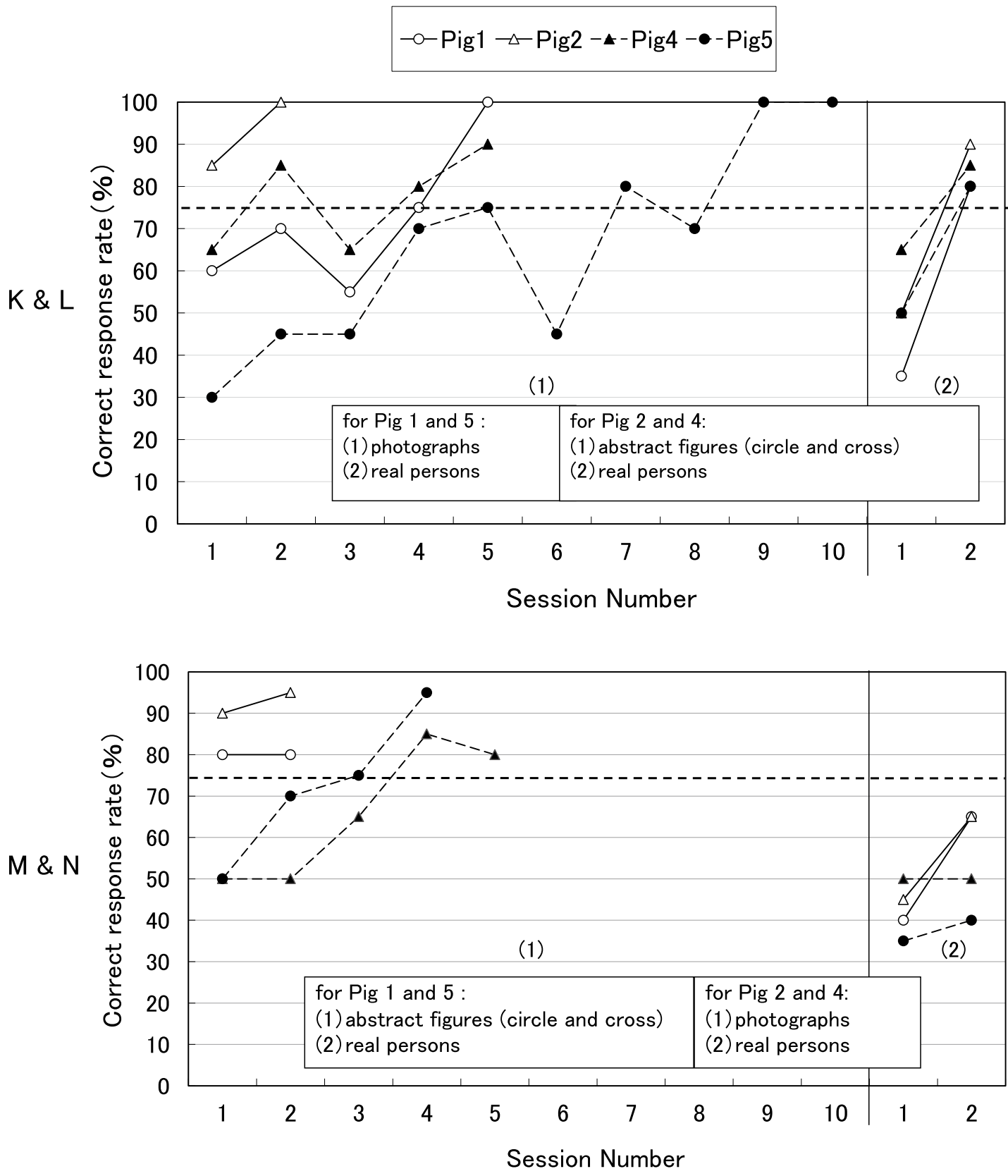

Figure 4. The correct response rate of each pig in Experiment 3. The dotted horizontal line indicates the criterion of discrimination (75\% correct choice rate: $p<.05$ by Chi square test).

when they were tested with the two people (either $\mathrm{K} \& \mathrm{~L}$ and $\mathrm{M} \& \mathrm{~N}$ ), their performance dropped sharply in the 1st session. All pigs exceeded $75 \%$ correct choice rate in the 2nd session of the test between the two people $\mathrm{K}$ and $\mathrm{L}$, regardless of whether they had previously learned to discriminate between photographs of the two people or between two abstract figures. In the test of $\mathrm{M}$ and $\mathrm{N}$, all pigs failed to discriminate between the people. Pigs that learned to discriminate between the photos of the people did not 
learn to discriminate between the two people faster than did pigs that learned to discriminate between two abstract figures.

\section{Discussion}

Our study confirms previous studies (Koba \& Tanida, 1999, 2001; Tanida \& Nagano, 1998) in showing that pigs can discriminate between individual people wearing the same colour clothes. Our results also show that pigs can learn to discriminate between two dimensional photographs of people. However, they appear not to generalize their learned discriminations from people to photographs of those people.

In experiment 1 , none of the pigs discriminated between the photographs of the people after they learned to discriminate between the people themselves. If the pigs had the ability of using knowledge of the visual image of real people to discriminate the photographs of the same people, they should have fulfilled the criterion at 1st session. In experiment 2, which was the reverse treatment of experiment 1, 2 pigs appeared to discriminate between the photos of the two people, suggesting that these particular pigs might have an ability to use the knowledge of photographic images for the discrimination of people. However, the other pigs failed to fulfill the success criterion, and these pigs showed this ability with only 1 out of 3 pairs of people. Thus, it is likely that pigs find it difficult to generalize from photographs to real people.

Experiment 3 tested whether pigs that had previously learned to discriminate between photographs of two people would learn to discriminate between the two people faster than pigs that had learned to discriminate between two abstract figures. All 4 pigs exceeded the criterion of success in the 2nd session with the two people $\mathrm{K}$ and $\mathrm{L}$. This was so irrespective of whether the pigs had previously learned to discriminate between photos of these two people or between two abstract figures. The pigs had much greater difficulty in discriminating between the other two people $\mathrm{M}$ and $\mathrm{N}$. It may be that pigs found it easier to discriminate between a man and a woman than between two women, and it is possible that this discrimination of real people involved use of other sensory modalities in addition to vision although olfactory cues were controlled as much as possible. And previous experience with photographs of these two people did not help the pigs learn to discriminate between the two people. This suggests that the pigs did not use the visual information of photograph to discriminate real people. Rather, it is more likely that the pigs learned to discriminate the photographs during the sessions because most pigs spent some sessions to fulfill the criterion.

Two age groups of pigs were used in the experiment and the age difference was 2 months. We found that younger pigs relatively learn slower than older pigs in training sessions before tests, but there were no differences in test performance.

In our study, the pigs appear not to discriminate the people based on their photograph. In contrast to our results, research on other species suggests that some species can discriminate people based on their photographs. Watanabe (1997) demonstrated the pigeon's ability to discriminate real objects from their pictures and that the pigeons not only can discriminate real objects and their pictures but also can see the pictures as representations of real objects. There are small populations of cells in the temporal cortex of sheep which respond preferentially to projected images of faces (Kendrick, 1991) and the sight of a human body shape (Kendrick \& Baldwin, 1989). Koba and Tanida (2007) tested whether the ponies that discriminated a rewarder and a non-rewarder, could discriminate their twodimensional photograph within two sessions. The ponies successfully discriminated the photograph of a female rewarder from that of a male non-rewarder but one pony could not discriminate the photograph of the rewarder from that of a female non-rewarder. The results indicate the possibility that 
ponies might be able to transfer knowledge of visual cues of people to discrimination of photographic images. At this point, we are unable to say whether these different results reflect a real difference between pigs and other species or whether the results reflect some aspect of our experimental set-up. Photographing reduces the visual information of real objects. For instance, photographs are the two-dimensional representation of the three-dimensional world. If the subjects are animated objects such as animals and humans, the movement is lost in photographs. There is a possibility that pigs have the potential ability to discriminate people based on their photographs but they could not do so in this experiment because of the lack of movement in the photographs. In the future study, video image of humans as well as photographs should be shown to the pigs.

\section{Conclusion}

Our results show that pigs can discriminate between people and between photographs of people, but they appear not to discriminate the people based on their photograph. Further studies using video image of moving objects such as humans and animals as visual stimuli should be conducted to clarify their ability of transferring knowledge of the three-dimensional world to two-dimensional images or vice versa.

\section{Acknowledgements}

This work was supported in part by the Invitation Fellowship for Research in Japan (Short-Term) from Japan Society for the Promotion of Science. We also thank Ms. M. Kaneda for assisting the work.

\section{References}

Boivin, X., Garel, J. P., Mante, A., \& Le Neindre, P. 1998 Beef calves react differently to different handlers according to the test situation and their previous interactions with their caretaker. Applied Animal Behaviour Science, 55, 245-258.

Boivin, X., Nowak, R., Després, G., Tournadre, H., \& Le Neindre, P. 1997 Discrimination between shepherds by lambs reared under artificial conditions. Journal of Animal Science, 75, 2892-2898.

Davis, H., Norris, C., \& Taylor, A. 1998 Whether ewes know me or not: the discrimination of individual humans by sheep. Behavioural Processes, 43, 27-32.

de Passillé, A. M., Rushen, J., Ladewig, J., \& Petherick, C. 1996 Dairy calves' discrimination of people based on previous handling. Journal of Animal Science, 74, 969-974.

Gellermann, L. W. 1933 Chance orders of alternating stimuli in visual discrimination experiments. The Journal of Genetic Psychology, 42, 206-208.

Kendrick, K. M. 1991 How the sheep's brain controls the visual recognition of animals and humans. Journal of Animal Science, 69, 5008-5016.

Kendrick, K. M., Atkins, K., Hinton, M. R., Broad, K. D., Fabre-Nys, C., \& Keverne, B. 1995 Facial and vocal discrimination in sheep. Animal Behaviour, 49, 1665-1676.

Kendrick, K. M., Atkins, K., Hinton, M. R., Heavens, P., \& Keverne, B. 1996 Are faces special for sheep? Evidence from facial and object discrimination learning tests showing effects of inversion and social familiarity. Behavioural Processes, 38, 19-35.

Kendrick, K. M., \& Baldwin, B. A. 1989 Visual responses of sheep temporal cortex cells to moving and stationary human images. Neuroscience Letters, 100, 193-197.

Koba, Y., \& Tanida, H. 1999 How do miniature pigs discriminate between people? The effect of exchanging cues between a non-handler and their familiar handler on discrimination. Applied Ani mal Behaviour Science, 61, 239-252.

Koba, Y., \& Tanida, H. 2001 How do miniature pigs discriminate between people? Discrimination between people 
wearing coveralls of the same colour. Applied Animal Behaviour Science, 73, 4558.

Koba, Y., \& Tanida, H. 2007 Ability of ponies to discriminate between people. Japanese Journal of Human Animal Relations, 19, 75-86 (in Japanese).

Munksgaard, L., de Passillé, A. M., Rushen, J., \& Ladewig, J. 1999 Dairy cows' use of colour cues to discriminate between people. Applied Animal Behaviour Science, 65, 1-11.

Munksgaard, L., de Passillé, A. M., Rushen, J., Thodberg, K., \& Jensen, M. B. 1997 Discrimination of people by dairy cows based on handling. Journal of Dairy Science, 80, 1106-1112.

Nicol C. J., \& Pope, S. J. 1994 Social learning in sibling pigs. Applied Animal Behaviour Science, 40, 31-43.

Rybarczyk, P., Koba, Y., Rushen, J., Tanida, H., \& de Passillé, A. M. 2001 Can cows discriminate people by their face? Applied Animal Behaviour Science, 65, 175-189.

Rybarczyk, P., Rushen, J., \& de Passillé, A. M. 2003 Recognition of people by dairy calves using colour of clothing. Applied Animal Behaviour Science, 81, 307-319.
Tanida, H., Miura, A., Tanaka, T., \& Yoshimoto, T. 1994 The role of handling in communication between humans and weanling pigs. Applied Animal Behaviour Science, 40, 219-228.

Tanida, H., Miura, A., Tanaka, T., \& Yoshimoto, T. 1995 Behavioral response to humans in individually handled weanling pigs. Applied Animal Behaviour Science, 42, 249-260.

Tanida, H., \& Nagano, Y. 1998 The ability of miniature pigs to discriminate between a stranger and their familiar handler. Applied Animal Behaviour Science, 56, 149-159.

Tanida, H., Senda, K., Suzuki, S., Tanaka, T., \& Yoshimoto, T. 1991 Color discrimination in weanling pigs. Animal Science and Technology, 62, 1029-1034.

Taylor, A., \& Davis, H. 1998 Individual humans as discriminative stimuli for cattle (Bos taurus). Applied Animal Behaviour Science, 58, 13-21.

Watanabe, S. 1997 Visual discrimination of real objects and pictures in pigeons. Animal Learning \& Behavior, 25, 185-192. (2010. 7.29 受稿, 2012. 2. 3 受理) 